\title{
Indicadores econômico-financeiros e o retorno das ações de empresas listadas na
}

B3

\section{Economic and financial indicators and the return of the shares from enterprises listed on B3}

\author{
Leonardo Flach Doutor em Contabilidade e Finanças. Universidade Federal de Santa Catarina (UFSC) - Brasil. \\ leonardo.flach@gmail.com \\ Luísa Karam de Mattos Doutoranda em Administração. Universidade Federal de Santa Catarina (UFSC) - Brasil. \\ luisakmattos@gmail.com
}

\section{RESUMO}

Esta pesquisa tem por objetivo analisar a correlação entre indicadores econômico-financeiros e o retorno das ações de empresas listadas na B3, para o período de 2007 a 2016 . O método de pesquisa é quantitativo, e foi selecionada uma amostra de 56 empresas que apresentavam valores válidos para o período. Os resultados demonstram que, dos 2.072 coeficientes examinados, 456 apresentaram forte correlação com o retorno das ações, e 44 apresentaram correlação muito forte. Constatou-se uma correlação fraca entre os indicadores individuais e a cotação das ações. Analisando os coeficientes que demonstraram forte correlação, o grupo de indicadores mais representativo foi o de endividamento. No grupo de coeficientes com correlação muito forte, o grupo de indicadores mais expressivo foi o de lucratividade. Por fim, o teste de hipóteses por meio da estatística $t$ para uma amostra permitiu inferir a existência de variação entre cada categoria de indicadores e a cotação das ações.

Palavras-chave: Indicadores econômico-financeiros. Retorno das ações. B3.

\section{ABSTRACT}

This research aims to analyze the correlation between economic and financial indicators and the return of shares of companies listed on B3, from 2007 to 2016. The research method is quantitative and has a sample of 56 companies. The results show that, after analyzing 2072 coefficients, 456 of them showed a strong correlation with stock returns, and 44 of them showed a very strong correlation. There was a weak correlation between individual indicators and stock prices. After analyzing the coefficients that showed a strong correlation, the most representative group of indicators was the group of indebtedness. In the group of coefficients with very strong correlation, the more expressive group of indicators was the profitability. Finally, the hypotheses test through statistics allowed to infer the existence of variation between each category of indicators and the price of shares.

Keywords: Economic and financial indicators. Return on shares. B3. 


\section{INTRODUÇÃO}

Investir em ações implica escolher uma ou mais empresas para aplicar seu dinheiro e se tornar sócio; porém, tal tomada de decisão está sujeita aos riscos do mercado mobiliário e sua característica de imprevisibilidade. $O$ valor das ações sofre influência de inúmeros e distintos fatores, tanto internos à empresa quanto externos, como os derivados de especulações e variáveis ambientais. Visando auxiliar a tomada de decisões, os investidores possuem a sua disposição diversas técnicas e métodos para análise das informações. Uma dessas modalidades disponíveis é o diagnóstico da situação empresarial por meio de indicadores econômico-financeiros, apurados a partir das demonstrações, no caso, daquelas publicadas.

De acordo com Assaf Neto e Lima (2017) a análise das demonstrações financeiras possibilita a avaliação do desempenho geral da organização em estudo, a fim de diagnosticar a situação atual e gerar resultados úteis para prever tendências futuras. De fato, pretende-se detectar o impacto das decisões financeiras sobre a liquidez, estrutura patrimonial e rentabilidade, sendo que a utilização de índices representa o procedimento mais usualmente empregado. Além disso, ressalta-se que um indicador isolado pode não conter informações significantes, sendo a posição mensurada mais adequadamente por um conjunto de índices comparados temporal e setorialmente.

Gitman (2002, p. 102) explica que a avaliação desses indicadores é atrativa por permitir o exame dos "níveis atuais e futuros de risco e retorno" das companhias, sendo que o preço da ação é afetado diretamente por tais níveis. $O$ autor afirma que as variações nos índices têm relações com os retornos das respectivas ações. Outro posicionamento oportuno é o de Graham (2007, p. 30), quando destaca que "operação de investimento é aquela que, após análise profunda, promete a segurança do principal e um retorno adequado". As operações que não atendem a essas condições são especulativas. Depreende-se da afirmação, a opinião do autor frente à apreciação das demonstrações, no que se refere à importância do investidor em conhecer seu investimento, com o intuito de fundamentar o julgamento e não se tornar em mera especulação.

Por fim, cabe ressalvar que as perspectivas "de crescimento físico em um negócio não significam lucros óbvios para os investidores" (GRAHAM, 2007, p. 17). Tal conclusão enfatiza que o desempenho econômico-financeiro mensurado pelos indicadores não é o único determinante do retorno das ações, existindo outros fatores que igualmente exercem influência, sendo o empenho empregado no estudo dos investimentos útil para entender e aplicar com maior probabilidade de acerto.

Diante do que foi exposto, busca-se analisar a correlação entre indicadores econômico-financeiros e o retorno de ações listadas na B3 referente ao período de 2007 a 2016. Para isso, são foram levantados os dados econômicos e financeiros das empresas listadas na Bolsa de Valores, Mercadorias e Futuros de São Paulo (B3) e definiu-se um grupo amostral. Em seguida, identificou-se os indicadores econômico-financeiros destas empresas e o retorno de suas ações. A partir destes dados, foi possível realizar análise estatísticas para verificação do impacto de indicadores econômico-financeiros sobre o retorno das ações.

\section{REVISÃO DA LITERATURA}

A busca pela verificação de correlação entre indicadores econômico-financeiros e o retorno das ações já foi tema de outras pesquisas. $\mathrm{O}$ trabalho de Mombach (2012, p. 12), por exemplo, teve por objetivo identificar e analisar a variação conjunta dos indicadores econômico-financeiros das empresas e dos retornos de suas ações. $O$ autor analisou seis Indicadores de Liquidez, onze Indicadores de Prazos Médios e de Giro, onze Indicadores de Endividamento, seis Indicadores de Rentabilidade e seis Indicadores de Lucratividade, totalizando quarenta indicadores e cinco categorias, conforme Quadro 1. 
Quadro 1 - Indicadores econômico-financeiros das empresas analisados nesta pesquisa

\begin{tabular}{|l|}
\hline Indicadores de Liquidez \\
\hline Liquidez geral \\
\hline Liquidez absoluta, imediata ou instantânea \\
\hline Liquidez corrente \\
\hline Liquidez seca \\
\hline Solvência geral \\
\hline Capital de giro (ou circulante) líquido \\
\hline
\end{tabular}

\begin{tabular}{|l|}
\hline Indicadores de Prazos Médios e de Giro \\
\hline Prazo Médio de Recebimento de Vendas (PMRV) \\
\hline Giro das Duplicatas a Receber \\
\hline Prazo Médio de Pagamento de Compras (PMPC) \\
\hline Giro das Contas a Pagar \\
\hline Prazo Médio de Renovação de Estoques (PMRE) \\
\hline Giro dos Estoques \\
\hline Giro do Ativo Permanente \\
\hline Giro do Ativo (ou do Ativo Total) \\
\hline Giro do Ativo Total Médio \\
\hline Giro do Patrimônio Líquido \\
\hline Giro do Ativo Operacional (RAO) \\
\hline
\end{tabular}

\section{Indicadores de Rentabilidade}

Retorno sobre o Ativo Total (ROA)

Retorno sobre o Ativo Total Médio

Retorno sobre o Patrimônio Líquido (ROE) 1

Retorno sobre o Patrimônio Líquido (ROE) 2

Retorno sobre o Capital Social Realizado

Retorno sobre o Investimento Operacional

\begin{tabular}{|l|}
\hline Indicadores de Lucratividade \\
\hline Margem Bruta \\
\hline Margem Operacional \\
\hline Margem Não Operacional \\
\hline Margem Líquida \\
\hline Lucro por Ação (LPA) \\
\hline Índice Preço/Lucro (P/L) \\
\hline
\end{tabular}

\begin{tabular}{|l|}
\hline Indicadores de Endividamento \\
\hline Endividamento Geral \\
\hline Exigível a Longo Prazo / Patrimônio Líquido \\
\hline Capitalização a Longo Prazo \\
\hline Participação de Capitais de Terceiros \\
\hline Composição do Endividamento \\
\hline Imobilização do Capital Próprio \\
\hline Imobilização do Patrimônio Líquido \\
\hline Imobilização dos Recursos Não Correntes \\
\hline Fluxo de Caixa / Passivo Exigível Total \\
\hline Fluxo de Caixa / Financiamentos a Longo Prazo \\
\hline Garantia de Capital de Terceiros \\
\hline
\end{tabular}

Fonte: elaboração própria (2019).

Os indicadores acima elencados foram escolhidos a partir da combinação de diversas literaturas sobre o tema, originando diversas fórmulas a fim de obter seus valores. Os índices, em sua maioria, são obtidos a partir de quocientes de dois dados, cujos resultados demonstram a proporção que um contém o outro ou suas relações. A seguir são apresentados quadros com as fórmulas utilizadas para o cálculo dos indicadores analisados.

Mombach $(2012$, p. 63) concluiu que, com relação às categorias de indicadores, "em termos gerais, foi evidenciada correlação média moderada" para todas, sendo identificada direção "positiva para as categorias de 'Indicadores de Liquidez', 'Indicadores de Rentabilidade', 'Indicadores de Lucratividade' e 'Indicadores de Prazos Médios e de Giro'", e apenas "para os 'Indicadores de Endividamento' a direção encontrada foi negativa".

Outra análise feita, a partir da realização de teste de hipóteses, examinou a aceitação da hipótese nula de que "não há evidência de variação conjunta". Por meio do cálculo da estatística do teste foi permitido rejeitar tal hipótese nula e comprovar a hipótese alternativa de "existência de variação conjunta entre os 
indicadores econômico-financeiros e os retornos das ações", considerando um nível de significância de 5\% (MOMBACH, 2012, p. 63-64).

Por fim, avaliando os indicadores individualmente, Mombach (2012, p. 64) constatou que o indicador "Lucro por Ação (LPA)" foi o que apresentou maior valor estatístico de correlação média. Na sequência destacam-se os indicadores "Fluxo de Caixa / Passível Exigível Total" e "Fluxo de Caixa / Financiamentos a Longo Prazo", inseridos na categoria de "Indicadores de Endividamento". Em quarto e quinto lugar na listagem em ordem decrescente de força de correlação média encontram-se, respectivamente, os indicadores "Giro do Ativo (ou do Ativo Total)" e "Giro do Ativo Operacional (RAO)", ambos indicadores da categoria "Indicadores de Prazos Médios e de Giro".

Diante do resultado dos dados, o autor concluiu que, apesar da correlação encontrada ter sido moderada para os indicadores e suas categorias, pela análise individual de cada empresa muitos dos valores obtidos apresentaram correlação média forte ou muito forte. Ao final, foi verificado que " $35 \%$ dos coeficientes de correlação calculados (não médios) caracterizam-se como fortes e muito fortes" (MOMBACH, 2012, p. 65).

Além do trabalho de Mombach (2012), Bastos (2008, p. 22) buscou "verificar quais os indicadores econômico-financeiros mais relevantes para avaliação de empresas por setor econômico" e uma das perguntas que o autor procurava responder era: "Quais indicadores assumem realmente relevância para cada setor econômico?". Em seu estudo, Bastos (2008) analisou 40 empresas de cinco setores econômicos: comércio, indústria, serviços, agroindústria e de serviços públicos. Os indicadores pesquisados para cada setor foram aqueles identificados nas Teses e Dissertações dos cursos de doutorado e mestrado em Ciências Contábeis, dos Programas de Pós-Graduação recomendados pela CAPES, defendidas durante o período de 1996 a 2006. O método de pesquisa aplicado por Bastos $(2008$, p. 78$)$ foi a análise fatorial, a qual visa a demonstrar "as estruturas das relações entre as variáveis, buscando um menor conjunto possível de fatores, isto é, a reunião de proposições segundo a mesma tendência de correlação estatística, para se fazer julgamentos de aspectos que têm a mesma relevância frente ao conjunto de indicadores". Bastos $(2008$, p. 7$)$ concluiu que apenas no setor de agroindústria não se pôde encontrar semelhança entre os dois conjuntos de indicadores, e que "os indicadores de liquidez geral e liquidez corrente são os indicadores que melhor se ajustam aos conjuntos de todos os setores econômicos".

Nagano, Merlo e Silva (2003) publicaram outro estudo na área, intitulado "As Variáveis Fundamentalistas e Seus Impactos na Taxa de Retorno de Ações no Brasil". O artigo objetivou "verificar se outras variáveis fundamentalistas, além da variável beta, são importantes na explicação das variações nas rentabilidades dos ativos" (NAGANO; MERLO; SILVA, 2003, p. 14). Tal coeficiente beta é aquele utilizado para medir o "risco não-diversificável", que segundo o "modelo de determinação de preços de ativos, mais conhecido por sua sigla em inglês CAPM" (Capital Asset Pricing Model) "está positivamente e (linearmente) relacionado" com o "retorno esperado de um título" (NAGANO; MERLO; SILVA, 2003, p. 14). Assim, os autores procuraram "verificar se o mercado acionário se comportou conforme a teoria Capital Asset Pricing Model (CAPM), ou se existiram outras variáveis significativas para a análise dos retornos das ações negociadas na Bolsa de Valores de São Paulo (Bovespa)" (NAGANO; MERLO; SILVA, 2003, p. 13). Para isso, Nagato, Merlo e Silva (2003, p. 18) utilizaram as "técnicas de regressão linear simples e múltipla em uma abordagem cross-section". Após a aplicação do método, a pesquisa constatou que existem também "relações significativas entre as rentabilidades das ações e algumas das variáveis fundamentalistas analisadas" (NAGANO; MERLO; SILVA, 2003, p. 24), e que "variáveis, como lucro/preço, valor de mercado, valor patrimonial/preço e liquidez, apresentaramse até mais significativas na explicação das variações das rentabilidades das ações que o próprio beta" (NAGANO; MERLO; SILVA, 2003, p. 21).

Fritzen (2004, p. 11) objetivou identificar "os fatores determinantes dos preços das ações no Mercado Acionário do Brasil", analisando o período de janeiro de 1995 a maio de 2003, totalizando 101 meses. O tamanho da amostra dependeu do mês em estudo, resultando em média, 111 empresas. Da mesma forma, os fatores foram definidos mensalmente, gerando em média 56 fatores para cada mês, divididos em seis grupos (de risco, de liquidez, de barateamento, de rentabilidade, técnicos e setoriais). $O$ autor aplicou como método de pesquisa o Modelo de Fator de Retorno Esperado, o qual se trata "de um modelo estatístico de previsão de retornos - regressão múltipla com dados cross-section" (FRITZEN, 2004, p. 31). Após as análises, os resultados 
alcançados demonstraram "que, a um nível de confiança de $90 \%$, são cinco os fatores que exercem influência sobre o preço das ações" (FRITZEN, 2004, p. 55). Fritzen (2004, p. 55) concluiu que "o fator com maior significância estatística foi o retorno sobre o patrimônio líquido, pertencente à família de medidas de rentabilidade".

\section{MÉTODO DE PESQUISA}

A presente pesquisa envolve a elaboração de um artigo científico, o qual conforme Lakatos e Marconi (2017) representa um pequeno estudo sobre uma questão científica, divergindo dos trabalhos científicos por possuir dimensão e conteúdo reduzidos, embora sejam completos. Além disso, mediante a elucidação da metodologia aplicada e seu processamento, permite que a experiência seja repetida.

Igualmente ao trabalho referência, esta pesquisa apresenta-se como descritiva quantitativa, ex post facto, e inclui teste de hipóteses. De acordo com Gil (2010, p. 27), a pesquisa descritiva (uma das classificações segundo os objetivos gerais) objetiva descrever as "características de determinada população", podendo "ser elaboradas também com a finalidade de identificar possíveis relações entre variáveis". A pesquisa é classificada como quantitativa devido à natureza dos dados, uma vez que as variáveis envolvem elementos numéricos. $A$ expressão ex post facto significa que os estudos são "feitos de trás para frente, depois que os fatos ocorreram. Ou, em outras palavras: partem do consequente (a doença) para o antecedente (a exposição ao fator de risco)" (GIL, 2017, p. 34).

O procedimento do teste de hipóteses permite, "com os dados amostrais, testar a veracidade" de "ideias sobre a população em estudo", sendo que tais ideias representam as hipóteses de pesquisa, as quais "poderão ser testadas por técnicas estatísticas denominadas testes de hipóteses ou testes de significância" (BARBETTA, 2011, p. 179). Assim, os testes de hipóteses servem, segundo Barbetta (2011, p. 180), para "verificar se os dados fornecem evidência suficiente para que se possa aceitar como verdadeira a hipótese de pesquisa", afirmando, com certa confiança, que a resposta encontrada não é meramente casual.

Para isso, são definidas duas hipóteses: a hipótese nula, a qual consiste em uma "negação daquilo que o pesquisador deseja provar"; e a hipótese alternativa, aceita quando há rejeição da primeira, que representa, em geral, aquilo que se busca provar com a pesquisa (BARBETTA, 2011, p. 181). No presente artigo procura-se verificar a existência de associação entre os indicadores econômico-financeiros e o retorno de ações listadas na B3, sendo a medida desta associação a média aritmética $(\mu)$. São, então, estabelecidas as seguintes hipóteses:

Hipótese Nula $\left(\mathbf{H}_{\mathbf{0}}\right)$ - não há evidência de associação entre os indicadores econômico-financeiros e o retorno de ações listadas na $B 3 . \rightarrow \mathbf{H}_{0}: \boldsymbol{\mu}=\mathbf{0}$.

Hipótese Alternativa $\left(\mathbf{H}_{\mathbf{1}}\right)$ - há evidência de associação entre os indicadores econômico-financeiros e o retorno de ações listadas na B3. $\rightarrow \mathbf{H}_{\mathbf{1}}: \boldsymbol{\mu} \neq \mathbf{0}$.

$O$ teste que permite a verificação de uma afirmação da média populacional com base em uma estatística obtida de uma amostra é o teste da estatística $t$, encontrada com base na fórmula a seguir:

$$
t=\frac{(\bar{x}-\mu)}{s / \sqrt{n}}
$$

Onde: " $\bar{x}$ " é a média da amostra; " $\mu$ " é a média da população, no caso zero; " $s$ " é o desvio padrão; e " $\sqrt{n}$ " é a raiz da amostra em análise.

Após essas definições iniciais, descreve-se o procedimento de levantamento das ações, das respectivas cotações e dos indicadores a serem analisados para aplicação dos procedimentos. Primeiramente, o levantamento dos dados ocorreu pelo software Economática, sendo buscadas todas as empresas da B3 e calculados as cotações de suas ações e cada um dos indicadores, para todas as empresas listadas. Após, foram retiradas as empresas sem valores para algum dos indicadores em algum dos anos e sem correspondente cotação para algum ano do período em estudo. Ressalta-se que as cotações foram obtidas conforme seu valor 
de fechamento (31 de dezembro de cada um dos anos) e com observação de tolerância, isto é, se não disponível cotação para a data de fechamento deve ser lançado o respectivo valor mais próximo dentro do ano respectivo.

Realizados todos esses procedimentos, foi possível obter uma amostra de 56 empresas, conforme Quadro . Cabe ainda mais uma observação: em comparação com o trabalho de Mombach (2012), três índices sofreram algumas ressalvas. O índice de Liquidez Imediata trouxe valor nulo para todas essas empresas selecionadas, sendo, portanto, retirado do estudo. $O$ índice de Margem Não Operacional não gerou valor para nenhuma empresa, não sendo possível utilizá-lo. E o índice de Retorno sobre o Investimento Operacional não apresentou valores para 97,3\% da amostra, sendo que somente $2,7 \%$ das empresas possuíam dados sobre tal indicador; portando, foi igualmente excluído da análise.

Quadro 2 - Lista de empresas selecionadas para compor a amostra desta pesquisa

\begin{tabular}{|c|c|c|c|}
\hline No & Empresa & No & Empresa \\
\hline 1 & Alpargatas & 29 & JBS \\
\hline 2 & Ambev S/A & 30 & Klabin S/A \\
\hline 3 & B2W Digital & 31 & Light S/A \\
\hline 4 & BRF SA & 32 & Lojas Americ \\
\hline 5 & Celul Irani & 33 & Lojas Marisa \\
\hline 6 & Cemar & 34 & M.Diasbranco \\
\hline 7 & Coelba & 35 & Marcopolo \\
\hline 8 & Comgas & 36 & Marfrig \\
\hline 9 & Copel & 37 & MRV \\
\hline 10 & Cremer & 38 & Natura \\
\hline 11 & Csu Cardsyst & 39 & Portobello \\
\hline 12 & Cyrela Realt & 40 & Profarma \\
\hline 13 & Dasa & 41 & Randon Part \\
\hline 14 & Dimed & 42 & Rodobensimob \\
\hline 15 & Duratex & 43 & Rossi Resid \\
\hline 16 & Embraer & 44 & Santanense \\
\hline 17 & Energisa & 45 & SLC Agricola \\
\hline 18 & Engie Brasil & 46 & Springs \\
\hline 19 & Eternit & 47 & Tecnisa \\
\hline 20 & Even & 48 & Tegma \\
\hline 21 & Eztec & 49 & Telef Brasil \\
\hline 22 & Fer Heringer & 50 & Terra Santa \\
\hline 23 & Gerdau & 51 & Tupy \\
\hline 24 & Gerdau Met & 52 & Usiminas \\
\hline 25 & Grendene & 53 & Viavarejo \\
\hline 26 & Helbor & 54 & Vulcabras \\
\hline 27 & Inds Romi & 55 & Weg \\
\hline 28 & lochpMaxion & 56 & Whirlpool \\
\hline
\end{tabular}

Fonte: elaboração própria (2019). 
Por fim, deve-se abordar o método de análise da correlação entre as variáveis, técnica utilizada para avaliar quantitativamente a associação entre os indicadores econômico-financeiros e o retorno de ações listadas na B3. Para isso, foi utilizado o Coeficiente de Correlação Linear de Pearson, "sendo referenciado pelo símbolo $\rho$ para a população e $r$ para a amostra" (MOMBACH, 2012, p. 20).

Segundo Barbetta (2011, p. 259), o coeficiente de correlação de Pearson pode ser obtido pela seguinte fórmula, "a qual é baseada nas observações originais":

$$
r=\frac{n \cdot \sum(X \cdot Y)-\left(\sum X\right) \cdot\left(\sum Y\right)}{\sqrt{n \cdot \sum X^{2}-\left(\sum X\right)^{2}} \cdot \sqrt{n \cdot \sum Y^{2}-\left(\sum Y\right)^{2}}}
$$

Entretanto, para encontrar o valor dos coeficientes de correlação de Pearson no presente estudo, foi utilizado o software Gretl, "um software multiplataforma para análise econométrica, escrito em linguagem C", "livre e de código aberto, podendo ser redistribuído e/ou modificado de acordo com os termos da Licença Pública Geral GNU (GPL) publicada pela Free Software Foundation". Os dados foram inseridos no Gret/ por meio de uma planilha Exce/com as variáveis e seus respectivos valores. No Quadro pode ser identificada a lista de variáveis em exame, com sua abreviatura, descrição e fonte:

Quadro 3 - Lista de variáveis pesquisadas

\begin{tabular}{|c|c|c|}
\hline $\begin{array}{c}\text { Abreviatura da } \\
\text { Variável }\end{array}$ & Descrição da Variável & Fonte \\
\hline \multicolumn{3}{|c|}{ INDICADORES DE LIQUIDEZ } \\
\hline \multicolumn{3}{|c|}{ Quanto maior a liquidez, melhor } \\
\hline LiqGer & Liquidez Geral & Software Economática \\
\hline LiqCor & Liquidez Corrente & Software Economática \\
\hline LiqSec & Liquidez Seca & Software Economática \\
\hline SolGer & Solvência Geral & Software Economática \\
\hline CapGir & Capital de Giro Líquido & Software Economática \\
\hline \multicolumn{3}{|c|}{ INDICADORES DE RENTABILIDADE } \\
\hline \multicolumn{3}{|c|}{ Quanto maior a rentabilidade, melhor } \\
\hline RentAt & Rentabilidade sobre o Ativo Total & Software Economática \\
\hline RentAt(med) & Rentabilidade sobre o Ativo Total Médio & Software Economática \\
\hline RentPat & Rentabilidade sobre o Patrimônio Líquido Total & Software Economática \\
\hline RentPat(med) & $\begin{array}{c}\text { Rentabilidade sobre o Patrimônio Líquido Total } \\
\text { Médio }\end{array}$ & Software Economática \\
\hline ROIC & Retorno sobre o Capital Social Investido & Software Economática \\
\hline \multicolumn{3}{|c|}{ INDICADORES DE LUCRATIVIDADE } \\
\hline \multicolumn{3}{|c|}{ Quanto maior a lucratividade, melhor } \\
\hline MrgBru & Margem Bruta & Software Economática \\
\hline MrgOpe & Margem Operacional & Software Economática \\
\hline MrgLiq & Margem Líquida & Software Economática \\
\hline LPA & Lucro Por Ação & Software Economática \\
\hline$P / L$ & Índice Preço/Lucro & Software Economática \\
\hline
\end{tabular}




\begin{tabular}{|c|c|c|}
\hline \multicolumn{3}{|c|}{$\begin{array}{c}\text { INDICADORES DE PRAZOS MÉDIOS E DE GIRO } \\
\text { Representa o tempo disponível para realização ou o tempo de renovação }\end{array}$} \\
\hline PMRecb & Prazo Médio de Recebimento de Vendas & Software Economática \\
\hline PMForn & Prazo Médio de Pagamento de Compras & Software Economática \\
\hline PMEstq & Prazo Médio de Renovação de Estoques & Software Economática \\
\hline GiroDup & Giro das Duplicatas a Receber & Software Economática \\
\hline GiroCP & Giro das Contas a Pagar & Software Economática \\
\hline GiroEst & Giro dos Estoques & Software Economática \\
\hline GiroAP & Giro do Ativo Permanente & Software Economática \\
\hline GiroAt & Giro do Ativo & Software Economática \\
\hline GiroPL & Giro do Patrimônio Líquido & Software Economática \\
\hline GiroAOp & Giro do Ativo Operacional & Software Economática \\
\hline GiroAtMed & Giro do Ativo Total Médio & Software Economática \\
\hline \multicolumn{2}{|r|}{ INDICADORES DE ENDIVIDAMENTO } & Quanto menor o endividamento, melhor \\
\hline Exg/At & Endividamento Geral & Software Economática \\
\hline ExgLP/PL & Exigível a Longo Prazo / Patrimônio Líquido & Software Economática \\
\hline DivLP/DivLP+PL & Capitalização a Longo Prazo & \\
\hline Exg/PL & Participação de Capitais de Terceiros & Software Economática \\
\hline PC/PNC & Composição do Endividamento & Software Economática \\
\hline AFx/PL & Imobilização do Capital Próprio & Software Economática \\
\hline ANC/PL & Imobilização do Patrimônio Líquido & \\
\hline ANC/PL+ExLP & Imobilização dos Recursos Não Correntes & Software Economática \\
\hline FC/Exg & Fluxo de Caixa / Passivo Exigível Total & Software Economática \\
\hline FC/FinLP & Fluxo de Caixa / Financiamentos a Longo Prazo & Software Economática \\
\hline $\mathrm{PL} / \mathrm{PL}+\mathrm{ExLP}$ & Garantia de Capital de Terceiros & Software Economática \\
\hline \multicolumn{3}{|c|}{ COTAÇÕES DAS AÇÕES (VARIÁVEL Y) } \\
\hline Fechamento & Cotação da ação no fechamento do ano & Software Economática \\
\hline
\end{tabular}

Fonte: elaboração própria (2019).

Ademais, para proceder ao cálculo das estatísticas do teste $t$ e elaborar as tabelas com frequências absolutas e relativas foi utilizado o software Microsoft Excel.

\section{ANÁLISE DOS RESULTADOS}

O resultado encontrado para a associação dos indicadores econômico-financeiros com a cotação das ações foi considerado para todos como uma relação fraca, com base no coeficiente de correlação de Pearson (r). Os valores calculados estão expostos na Tabela 1. 
Tabela 1 - Coeficiente de correlação $(r)$ de cada indicador com a cotação das ações

\begin{tabular}{lcllc}
\hline \multicolumn{1}{c}{ Indicador } & Coeficiente $(\boldsymbol{r})$ & Indicador & Coeficiente $(\boldsymbol{r})$ \\
\hline LiqGer & 0,008 & GiroCP & 0,036 \\
LiqCor & $-0,007$ & GiroEst & $-0,021$ \\
LiqSec & $-0,076$ & GiroAP & 0,093 \\
SolGer & 0,013 & GiroAt & 0,110 \\
CapGir & $-0,047$ & GiroPL & $-0,017$ \\
RentAt & 0,027 & GiroAO & 0,045 \\
RentAt & 0,036 & GiroAtMed & 0,114 \\
RenPat & $-0,012$ & ExgAt & $-0,064$ \\
RenPatmed & $-0,027$ & ExgLPPL & $-0,033$ \\
ROIC & $-0,010$ & DivLPDivLPPL & $-0,094$ \\
MrgBru & $-0,090$ & ExgPL & $-0,029$ \\
MrgOpe & $-0,038$ & PCPNC & 0,004 \\
MrgLiq & 0,001 & AFxPL & $-0,029$ \\
LPA & 0,268 & ANCPL & $-0,038$ \\
PL & $-0,006$ & ANCPLExLP & $-0,064$ \\
PMRecb & $-0,032$ & FCExg & $-0,016$ \\
PMPgto & $-0,037$ & FCFinLP & $-0,031$ \\
PMEstq & 0,059 & PLPLExLP & 0,110 \\
GiroDup & 0,053 & Fechamento & 1,000 \\
\hline
\end{tabular}

Fonte: Elaboração própria (2019).

Dos coeficientes apresentados, nota-se que os indicadores Lucro Por Ação (LPA), Giro do Ativo Total Médio (GiroAtMed), Garantia do Capital de Terceiros (PL/PL+ExLP) e Giro do Ativo (GiroAt) foram os quatro indicadores com maiores valores de correlação com a cotação das ações, todos acima de 0,1, correspondendo, respectivamente, a 0,268, 0,114, 0,1104 e 0,1103. Destaca-se que esses quatro maiores indicadores exibiram coeficiente positivo, evidenciando uma conexão direta, isto é, com um aumento no valor do indicador há um crescimento na cotação das ações.

Para melhor análise da associação, foi realizado um levantamento dos coeficientes de correlação de todos os indicadores com a cotação das ações, para cada uma das 56 empresas selecionadas, individualmente. Atingiu-se um total de 2.072 coeficientes. O resumo do resultado obtido com base na força da correlação pode ser visualizado na tabela a seguir.

Tabela 2 - Frequências por força de correlação dos coeficientes de todas as empresas

\begin{tabular}{|c|c|c|}
\hline Força & Frequência Absoluta (F) & Frequência Relativa (fo) \\
\hline Fraca & 865 & $41,7 \%$ \\
\hline Moderada & 707 & $34,1 \%$ \\
\hline Forte & 456 & $22,0 \%$ \\
\hline Muito Forte & 44 & $2,1 \%$ \\
\hline TOTAL & 2072 & $100,0 \%$ \\
\hline
\end{tabular}

Fonte: elaboração própria (2019). 
Do total dos 2.072 coeficientes de correlação $(r)$, observa-se que, apesar da maior frequência relativa, $41,7 \%$, representar força de correlação fraca, $24,1 \%$ dos coeficientes individuais de todas as empresas revelaram força de correlação forte ou muito forte.

Desses totais das frequências dos coeficientes por força da correlação, é interessante discriminar quanto cada indicador abarca do total da força de correlação. Estes dados são apresentados na Tabela 3.

Tabela 3 - Frequências dos coeficientes de correlação de todas as empresas por grupo de indicador

\begin{tabular}{|c|c|c|c|}
\hline Força & Indicador & Frequência & $f \%$ \\
\hline \multirow[t]{6}{*}{ Fraca } & Liquidez & 110 & $12,7 \%$ \\
\hline & Rentabilidade & 126 & $14,6 \%$ \\
\hline & Lucratividade & 119 & $13,8 \%$ \\
\hline & Prazos Médios e de Giro & 256 & $29,6 \%$ \\
\hline & Endividamento & 254 & $29,4 \%$ \\
\hline & TOTAL & 865 & $100,0 \%$ \\
\hline \multirow[t]{6}{*}{ Moderada } & Liquidez & 86 & $12,2 \%$ \\
\hline & Rentabilidade & 92 & $13,0 \%$ \\
\hline & Lucratividade & 80 & $11,3 \%$ \\
\hline & Prazos Médios e de Giro & 233 & $33,0 \%$ \\
\hline & Endividamento & 216 & $30,6 \%$ \\
\hline & TOTAL & 707 & $100,0 \%$ \\
\hline \multirow[t]{6}{*}{ Forte } & Liquidez & 78 & $17,1 \%$ \\
\hline & Rentabilidade & 56 & $12,3 \%$ \\
\hline & Lucratividade & 69 & $15,1 \%$ \\
\hline & Prazos Médios e de Giro & 118 & $25,9 \%$ \\
\hline & Endividamento & 135 & $29,6 \%$ \\
\hline & TOTAL & 456 & $100,0 \%$ \\
\hline \multirow[t]{6}{*}{ Muito Forte } & Liquidez & 6 & $13,6 \%$ \\
\hline & Rentabilidade & 6 & $13,6 \%$ \\
\hline & Lucratividade & 12 & $27,3 \%$ \\
\hline & Prazos Médios e de Giro & 9 & $20,5 \%$ \\
\hline & Endividamento & 11 & $25,0 \%$ \\
\hline & TOTAL & 44 & $100,0 \%$ \\
\hline
\end{tabular}

Fonte: Elaboração própria (2019).

Analisando os coeficientes que demonstraram força de correlação forte, os indicadores mais representativos foram os de endividamento, com 29,6\% do total de coeficientes classificados com tal força. Por outro lado, considerando força de correlação muito forte, os indicadores mais significativos consistiram naqueles de lucratividade, com $27,3 \%$ do total do grupo de força.

Considerando uma média de todos os coeficientes de correlação por empresa, identificou-se a ocorrências das forças médias de associação dos indicadores para cada uma das 56 empresas em exame. Verificou-se que duas empresas exibiram forças médias fortes para os coeficientes dos indicadores, 39 
empresas resultaram em forças médias moderadas e as 15 restantes forças médias fracas. Com base nos coeficientes médios de todas as empresas procedeu-se à realização do teste de hipóteses para verificar a existência de variação conjunta entre todos os indicadores e as cotações das ações. Substituindo os valores na fórmula explicitada na seção referente ao Método de pesquisa, obteve-se um valor para o teste $t$ estatístico bicaudal igual a 25,05 . Tendo em vista que o teste $t$ crítico bicaudal a um nível de confiança de $95 \%$ (significância $a=0,05$ ) equivale a 1,96, derivando uma região crítica abaixo de -1,96 e acima de 1,96, e que a estatística do teste tencontrada pertence a esse intervalo, pode-se rejeitar a hipótese nula e assumir a hipótese alternativa, inferindo que existe variação conjunta entre os indicadores médios de todas as empresas e as cotações das ações.

A partir dos coeficientes de correlação individual das empresas foi possível ainda calcular a média dos coeficientes para cada grupo de indicadores, a fim de verificar a existência de variação conjunta entre os grupos de indicadores e o retorno das ações. A Tabela 4 a seguir exibe os resultados obtidos para cada categoria de indicadores.

Tabela 4 - Coeficientes de correlação e força por categoria de indicadores

\begin{tabular}{lcc}
\hline \multicolumn{1}{c}{ Categoria de Indicadores } & Coeficiente & Força \\
\hline Liquidez & 0,420 & Moderada \\
Rentabilidade & 0,372 & Moderada \\
Lucratividade & 0,408 & Moderada \\
Prazos Médios e de Giro & $-0,379$ & Fraca \\
Endividamento & $-0,393$ & Fraca \\
\hline
\end{tabular}

Fonte: elaboração própria (2019).

Constatou-se que três categorias, Liquidez, Rentabilidade e Lucratividade, apresentaram força moderada de associação e as outras duas, Prazos Médios e de Giro e Endividamento, revelaram força de correlação fraca. Salienta-se, ainda, que somente as duas categorias com associação de força fraca originaram relação negativa, isto é, quanto maior o indicador menor a cotação da ação. Com relação aos indicadores com força moderada de associação, o indicador de Liquidez foi aquele com maior valor, derivando um coeficiente igual a 0,420, seguido do indicador de Lucratividade com coeficiente de 0,408.

Da mesma forma que com as médias dos coeficientes de correlação de todas as empresas, procedeuse ao cálculo dos testes $t$ estatísticos de cada uma das cinco categorias de indicadores buscando evidenciar a existência de variação conjunta por grupo. Utilizando a fórmula elucidada no Método de pesquisa, substituíram-se os valores constantes na Tabela 5 originando os testes $t$ estatísticos para cada categoria de indicadores.

Tabela 5 - Dados estatística do teste $t$

\begin{tabular}{|c|c|c|c|c|c|}
\hline & $\begin{array}{l}\text { Liquide } \\
z\end{array}$ & $\begin{array}{l}\text { Rentabilidad } \\
\text { e }\end{array}$ & $\begin{array}{l}\text { Lucratividad } \\
e\end{array}$ & $\begin{array}{l}\text { Prazos Médios e de } \\
\text { Giro }\end{array}$ & $\begin{array}{l}\text { Endividament } \\
0\end{array}$ \\
\hline Média amostral $(\overline{\mathrm{x}})$ & 0,420 & 0,372 & 0,408 & 0,379 & 0,393 \\
\hline \multicolumn{6}{|l|}{ Média populacional } \\
\hline$(\mu)$ & 0 & 0 & 0 & 0 & 0 \\
\hline Desvio padrão (s) & 0,194 & 0,232 & 0,179 & 0,111 & 0,153 \\
\hline Amostra (n) & 56 & 56 & 56 & 56 & 56 \\
\hline Teste $t$ & 16,19 & 12,02 & 17,06 & 25,54 & 19,18 \\
\hline
\end{tabular}

Fonte: Elaboração própria (2019). 
Mediante a técnica do teste de hipóteses, tendo como referência os valores dos testes $t$ estatísticos calculados e expostos na Tabela 5, verificou-se que para todas as categorias de indicadores foi comprovada a evidência de variação conjunta entre os indicadores e a cotação das ações. Conforme explanado anteriormente, como os testes $t$ estatísticos pertencerem ao intervalo de rejeição da hipótese nula, isto é, foram maiores que o teste $t$ crítico bilateral de 1,96 considerando um nível de significância de $95 \%$ (significância $a=0,05$ ), pode-se afirmar que existe variação conjunta entre cada categoria de indicadores e as cotações das ações.

Por fim, sintetizando a análise para determinados subsetores da B3, considerando uma tendência de uniformidade das empresas de cada classificação, foi elabora a Tabela $6 \mathrm{com}$ as frequências absolutas e relativas dos coeficientes de correlação por força e categoria de indicadores. Foram selecionados os seis setores que possuíam mais empresas com valores válidos para análise: alimentos processados, comércio, construção civil, energia elétrica, material de transporte, e tecidos, vestuário e calçados. Ressalta-se que nenhum apresentou coeficiente de correlação com força muito forte.

Tabela 6 - Frequências dos coeficientes de correlação por força, subsetor e categoria de indicadores

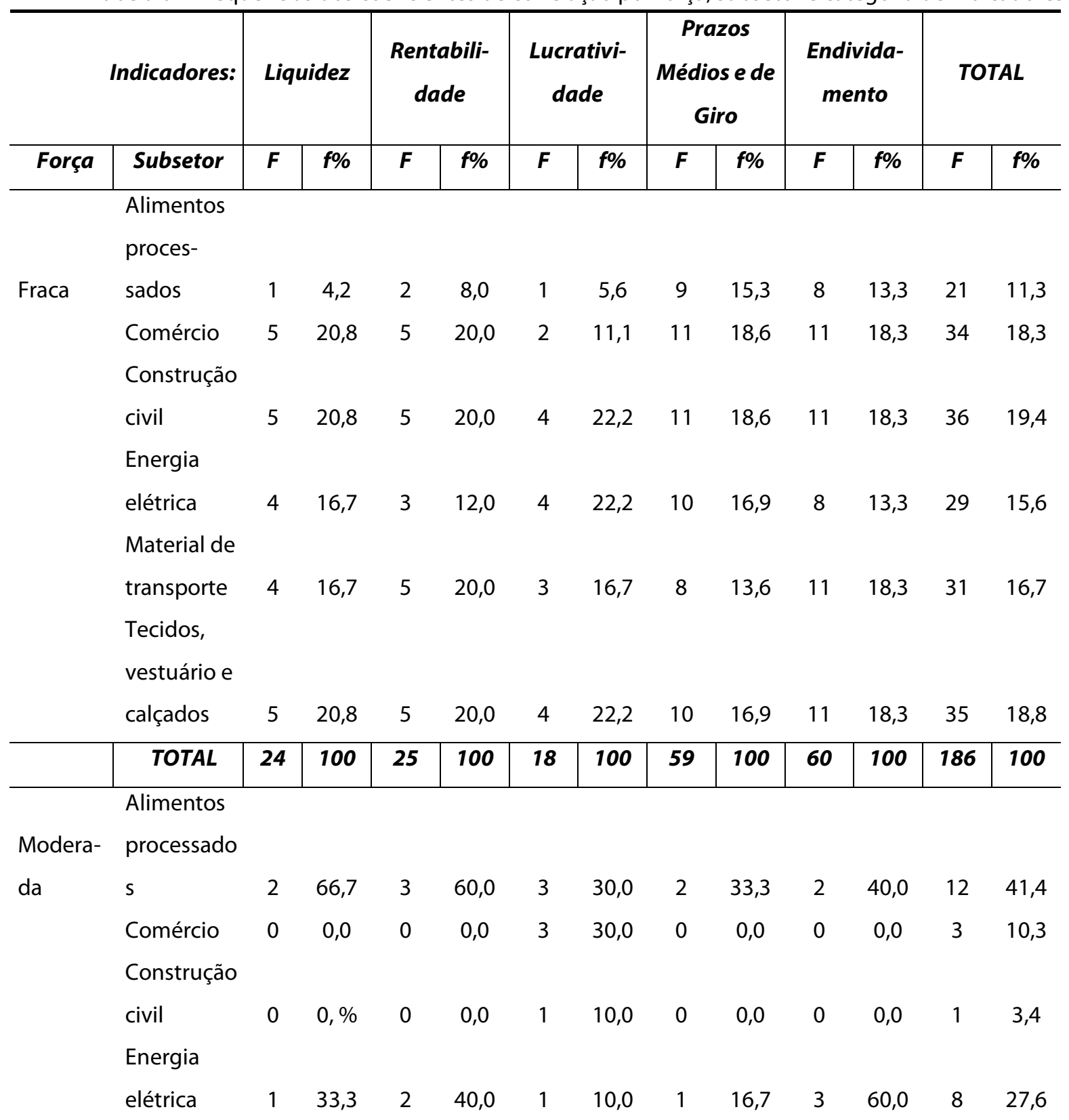


Material de

transporte

$0,0 \quad 0$

0,0

220,0

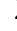

33,3

$0,0 \quad 4$

13,8

Tecidos,

vestuário e

\begin{tabular}{|c|c|c|c|c|c|c|c|c|c|c|c|c|c|}
\hline & calçados & 0 & 0,0 & 0 & 0,0 & 0 & 0,0 & 1 & 16,7 & 0 & 0,0 & 1 & 3,4 \\
\hline & TOTAL & 3 & 100 & 5 & 100 & 10 & 100 & 6 & 100 & 5 & 100 & 29 & 100 \\
\hline & Alimentos & & & & & & & & & & & & \\
\hline & proces- & & & & & & & & & & 100, & & \\
\hline \multirow[t]{12}{*}{ Forte } & sados & 2 & 66,7 & 0 & - & 1 & 50,0 & 0 & 0,0 & 1 & 0 & 4 & 57,1 \\
\hline & Comércio & 0 & 0,0 & 0 & - & 0 & 0,0 & 0 & 0,0 & 0 & 0,0 & 0 & 0,0 \\
\hline & Construção & & & & & & & & & & & & \\
\hline & civil & 0 & 0,0 & 0 & - & 0 & 0,0 & 0 & 0,0 & 0 & 0,0 & 0 & 0,0 \\
\hline & Energia & & & & & & & & & & & & \\
\hline & elétrica & 0 & 0,0 & 0 & - & 0 & 0,0 & 0 & 0,0 & 0 & 0,0 & 0 & 0,0 \\
\hline & Material de & & & & & & & & 100, & & & & \\
\hline & transporte & 1 & 33,3 & 0 & - & 0 & 0,0 & 1 & 0 & 0 & 0,0 & 2 & 28,6 \\
\hline & Tecidos, & & & & & & & & & & & & \\
\hline & vestuário e & & & & & & & & & & & & \\
\hline & calçados & 0 & 0,0 & 0 & - & 1 & 50,0 & 0 & 0,0 & 0 & 0,0 & 1 & 14,3 \\
\hline & TOTAL & 3 & 100 & 0 & - & 2 & 100 & 1 & 100 & 1 & 100 & 7 & 100 \\
\hline
\end{tabular}

Fonte: elaboração própria (2019).

Observa-se que dentro da força de correlação forte o setor com maior frequência foi o de alimentos processados, sendo o indicador de liquidez o mais expressivo. Examinando a força de associação moderada, igualmente o setor de alimentos processados foi aquele com maior frequência de coeficientes; porém, os indicadores de rentabilidade e lucratividade foram os mais significativos, sendo este último o com maior abundância de frequências no grau de força moderada levando em consideração todos os setores.

\section{CONSIDERAÇÕES FINAIS}

O artigo objetivou realizar um estudo para avaliar a correlação entre indicadores econômicofinanceiros e o retorno das ações de empresas listadas na B3 referente ao período de 2007 a 2016. A motivação partiu da característica de imprevisibilidade do mercado de ações, representando a pesquisa uma prática para auxílio na tomada de decisão por parte dos investidores, uma vez que os indicadores possibilitam o exame das condições e do desempenho financeiro das empresas.

As técnicas estatísticas apresentadas nesta pesquisa incluíram o teste de hipóteses, com a hipótese nula de que não há evidência de associação entre os indicadores econômico-financeiros e a cotação das ações, e a análise de correlação, por meio do coeficiente de correlação de Pearson.

A análise dos resultados permitiu constatar que a força de correlação entre os indicadores individuais e a cotação das ações foi fraca. Contudo, dos 2.072 coeficientes de correlação individual (obtidos dos indicadores de todas as empresas) examinados, 456 revelaram força de associação forte e 44 classificaram-se como muito forte, resultando em um percentual acumulado nessas duas forças de $24,1 \%$, valor significativo. 
Averiguando os coeficientes que demonstraram força de correlação forte, a categoria de indicadores mais representativa foi a de endividamento, com $29,6 \%$ do total de coeficientes enquadrados com tal força. Em contrapartida, considerando força de correlação muito forte, o grupo de indicadores com frequência mais significativa em relação do total da força foi o de lucratividade. Tais dados demonstram que os indicadores de endividamento são os que mais possuem forte associação com a cotação das ações, e que os indicadores de lucratividade são aqueles que mais apresentam correlação muito forte com a cotação das ações. Esta última informação é coerente, considerando que o Lucro por Ação (LPA) se encontra qualificado como de lucratividade, e é bastante atrativo para os investidores, sendo o mais expressivo dos indicadores individuais conforme apontado na Tabela 1 dentro da seção de Análise dos resultados. Assim, a lógica é: quanto maior o lucro por ação, mais investidores optam por adquirir as ações, levando a uma maior cotação.

As ocorrências das forças médias de associação dos indicadores médios para cada uma das 56 empresas em exame com a cotação das ações evidenciaram que duas empresas exibiram forças médias fortes, 39 empresas resultaram em forças médias moderadas e as 15 restantes forças médias fracas. Procedendo-se ao teste de hipóteses para tais valores médios, foi possível inferir que existe variação conjunta entre os indicadores médios de todas as empresas e as cotações das ações.

Com relação à variação conjunta de cada grupo de indicadores e a cotação das ações, concluiu-se que três categorias, Liquidez, Rentabilidade e Lucratividade, apresentaram força positiva moderada de associação, e as outras duas, Prazos Médios e de Giro e Endividamento, revelaram força de correlação negativa fraca. Os sinais dos coeficientes têm um comportamento lógico, sendo que apenas os indicadores de Prazos Médios e de Giro divergiram da conclusão obtida no trabalho de Mombach (2012); todavia, a lógica do sinal depende do indicador individual, sendo alguns racionalmente positivos e outros negativos. Salienta-se ainda que dos indicadores com força moderada de associação, o indicador de Liquidez foi aquele com maior valor, derivando um coeficiente igual a 0,420, seguido do indicador de Lucratividade com coeficiente de 0,408.

Procedendo-se ao teste de hipóteses para cada uma das cinco categorias de indicadores buscando evidenciar a existência de variação conjunta por grupo, comprovou-se a existência de variação conjunta entre os indicadores de cada categoria e a cotação das ações, a um nível de significância de 95\% (significância a = $0,05)$.

Para encerrar as análises, com base nas frequências dos coeficientes de correlação por força, subsetor da B3 e categoria de indicadores, restou demonstrado que dentro da força de correlação forte o setor com maior frequência foi o de alimentos processados e o indicador de liquidez foi o mais expressivo. Igualmente, examinando a força de associação moderada, o setor de alimentos processados foi aquele com maior frequência de coeficientes; porém, os indicadores de rentabilidade e lucratividade foram os mais significativos para o setor, sendo este último aquele com mais ocorrências no grau de força moderada levando em consideração todos os setores.

Considerando o resultado do estudo, vislumbra-se que o objetivo do artigo foi alcançado, sendo demonstrada a análise de correlação e confirmadas as hipóteses formuladas. Ademais, os resultados obtidos são frutos dos métodos estatísticos empregados, podendo ser reaplicados e readaptados para pesquisas posteriores. Como principal recomendação de estudos futuros, sugere-se a consolidação e cotejamento dos resultados das diversas pesquisas, a continuidade e aplicação em diferentes amostras e anos, bem como, a realização de métodos de regressão para os dados em que foi comprovada a correlação. Finalmente, importante destacar que o artigo não trouxe, nem procurou trazer, uma referência completa para o tema, apenas uma contribuição embasada metodologicamente aos interessados, sobretudo àqueles que investem em ações.

\section{REFERÊNCIAS}

ASSAF NETO, Alexandre; LIMA, Fabiano Guasti. Fundamentos de Administração Financeira. 3. ed. São Paulo: Atlas, 2017.

BARBETTA, Pedro Alberto. Estatística Aplicada às Ciências Sociais. 7. ed. Florianópolis: UFSC, 2011. 
BASTOS, Éder Claudio. Análise dos Indicadores Econômico-Financeiros Relevantes para Avaliação de Empresas. 2008. 151 p. Dissertação (Mestrado em Ciências Contábeis) - Programa de Pós-Graduação em Ciências Contábeis da Universidade Regional de Blumenau, Blumenau, 2008. Disponível em: http://www.bc.furb.br/docs/DS/2008/331492_1_1.pdf. Acesso em: 17 jun. 2017.

FRITZEN, Marcos. Fatores Determinantes dos Preços das Ações em Mercados Ineficientes: um estudo do mercado acionário brasileiro no período de 1995 a 2003. 2004. 112 p. Dissertação (Mestrado em Economia) Programa de Pós-Graduação em Economia da Faculdade de Ciências Econômicas da Universidade Federal do Rio Grande do Sul, Porto Alegre, 2004. Disponível em: http://www.lume.ufrgs.br/bitstream/handle/10183/6695/000445380.pdf?sequence=1. Acesso em: 17 jun. 2017.

GIL, Antonio Carlos. Como elaborar projetos de pesquisa. 6. ed. São Paulo: Atlas, 2017.

GITMAN, Lawrence J. Princípios de Administração Financeira. 7. ed. São Paulo: Harbra, 2002.

GRAHAM, Benjamin. O Investidor Inteligente: um guia prático de como ganhar dinheiro na bolsa. Rio de Janeiro: Bovespa, 2007. Disponível em: http://facisabhead.noip.org:8080/jspui/bitstream/123456789/365/1/0\%20Investidor\%20Inteligente\%20\%20Benjamin\%20Graham.pdf. Acesso em 08 maio 2017.

LAKATOS, Eva Maria; MARCONI, Marina de Andrade. Fundamentos de Metodologia Científica. 8. ed. São Paulo: Atlas, 2017.

MOMBACH, Heitor Becker. Relação entre os Indicadores Econômico-Financeiros e o Retorno das Ações. 2012. 98 f. Monografia (Especialização) - Programa de Pós-Graduação em Administração, Universidade Federal do Rio Grande do Sul, Porto Alegre, 2012. Disponível em: https://www.lume.ufrgs.br/bitstream/handle/10183/83566/000906792.pdf?sequence=1. Acesso em: 5 abr. 2017.

NAGANO, Marcelo Seido; MERLO, Edgard Monforte; SILVA, Maristela Cardoso da. As Variáveis Fundamentalistas e Seus Impactos na Taxa de Retorno de Ações no Brasil. Revista da FAE, Curitiba, v. 6, n. 2 p. 13-28, maio/dez. 2003. Acesso em: 17 jun. 2017. 